During phase one: the current collective syllabus will be mapped out using a standard reporting tool to collate all hospice education activity, highlight any gaps against national best practice and identify areas of current strength.

At the same time conversations will continue with all education providers across the education sector as to the feasibility of joining up all education in a collaborative setting.

Following this, information will be collated and a business case of options for hospice education will be put forward underpinned by support from Deloitte.

Conclusion The evaluation of this work will be ongoing and can be measured in simple terms by the degree of collaboration and output against the project aims.

\section{P-236 THE NATIONAL HOSPICE EDUCATION COLLABORATIVE: DEVELOPING UK HOSPICE POTENTIAL AS VOCATIONAL EDUCATION PARTNERS}

Sally Garbett. St Christopher's Hospice, London, UK

\subsection{6/bmjspcare-2016-001245.257}

In 2013 the need for high quality vocational education for the healthcare workforce gained increased relevance. Vocational qualifications became central to Health Education England Strategies and the Government announced revisions to Apprenticeships which combined with NHS workforce reforms to become a catalyst for change:
The project An appetite from hospices for collaboration and support for vocational education was proven in an 18-month pilot hospice consortium. Consequently, and with funding from CHKcharities.co.uk, the National Hospice Education Collaborative formed. The initial focus is building quality and capacity of vocational education, including nurse associate and degree level nurse apprenticeships. Economies of scale and sharing of expertise will benefit all involved. Work on other educational initiatives will emerge.

Sustainability Significant interest and two years' funding enables the establishment of a subscription model for sustainability.

\section{P-237 TICL - TEACHING, INFORMATION, CURIOSITY, LEARNING}

Kirra Moser. Peace Hospice Care, Watford, UK

10.1136/bmjspcare-2016-001245.258

Context The concept of protected learning time is not new. However, when organisational commitments become overwhelming, education is usually first to be side-lined. Historically, our protected learning time was clinically focussed and excluded many staff in our organisation.

TICL sessions were born in January 2016 and co-ordinated by the education team. For one hour every Tuesday afternoon, all staff and volunteers are welcome, and encouraged, to attend information sessions on varied topics.

The Francis Report (February 2013) highlighted the poor standards of care in the Mid Staffs NHS

Foundation Trust.

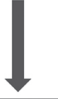

The Cavendish Review (July 2013) reported on the inconsistencies of care worker induction training resulting in The Care Certificate implementation in March 2015.

Health Education England (HEE) launched Talent for Care and Widening Participation; it matters

(October 2014) - a national strategy for a route from healthcare assistant to nurse, utilising vocational qualifications.

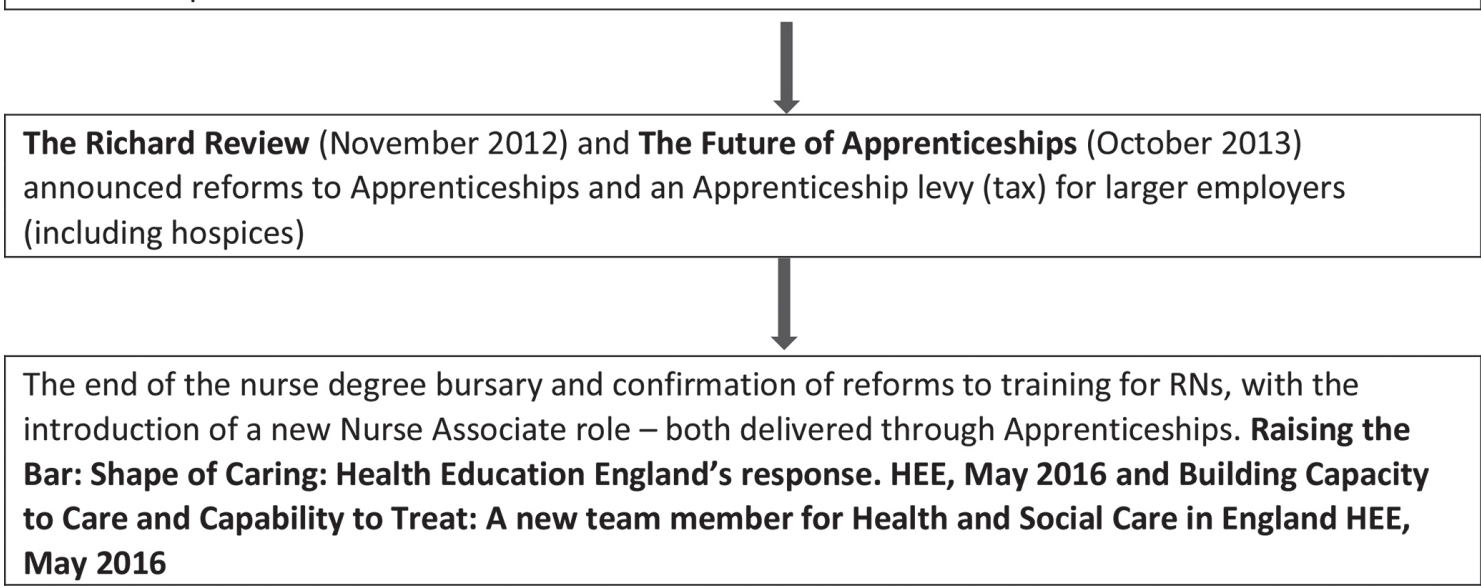


It is delivered in a relaxed and informal environment. The sessions encourage discussion, strengthen working relationships, break down boundaries across different aspects of the organisation, share experiences, improve morale, improve health and well-being and provide exposure to different subjects.

Aim To provide all staff across the organisation an opportunity to acquire new information and knowledge for professional and personal development.

Where possible, we choose topics to match local and national awareness days.

These sessions provide presentation experience opportunities, utilise hidden staff skills and engage local service providers. The sessions also provide a forum to share news and celebrate events. Recent topics have included:

- What is social media?

- Skin cancer awareness

- Eating salt

- Walk to the park

- Sharing stories

- Desert island discs - music reflection

- Mindfulness

- Laughter therapy

- Recording your learning

- Choices after death from a local funeral director.

Future topics include flower arranging, computer skills and continuing professional development sessions.

Evaluation and sustainability Feedback suggests the sessions are appreciated, useful and informative. Sessions are varied and interesting. Staff are encouraged to suggest topics. Directors are supportive and encouraging of staff attendance to these sessions. Staff can attend without guilt. Given numerous part time staff, we will trial alternating days to be more inclusive. Clinical training now stays in clinical areas.

All sessions incur no cost as all external speakers provide their services free of charge.

\section{P-238 A CROSS- ORGANISATIONAL APPROACH TO EDUCATION IN PALLIATIVE AND END OF LIFE CARE}

${ }^{1}$ Anna MacPherson, ${ }^{2}$ Jeanette Shepherd. 'East Lancashire Hospitals NHS Trust, Burnley, UK; ${ }^{2}$ Pendleside Hospice, Burnley, UK

\subsection{6/bmjspcare-2016-001245.259}

Context Increasing access to appropriate education and training in palliative and end-of-life care are widely recommended to improve patient care. Coordinating and delivering an up-to-date education programme to meet the needs of varied health and social care professionals takes significant time and resources. We decided to approach this from a locality perspective, aiming to make the most effective use of all resources available.

What is being done? All relevant local organisations agreed to be involved, including hospices, acute trust, community service providers, clinical commissioning groups and social care.

An overall strategy was developed following local consultation, and an action plan developed:
1 - Scope available resources and compile and publicise a training directory

2 - Look for urgent gaps in training and how they may be filled

3 - Develop a competency framework covering health and social care

4 - Map the competency framework to the training directory and ensure a fully rounded programme is in place

5 - Incentivise attendance at training.

Progress and outcomes

- A training directory has been developed, and its impact being measured by monitoring subsequent access to training

- Urgent gaps identified:

- Training in primary care on DNACPR and care in the last days of life. Locality based sessions held, attended by over 80 GPs; well-evaluated and well-attended

- Communication skills training - a coordinated programme is being developed, using trainers from each major provider

- A competency framework has just been developed and organisations are starting to link to appraisal and PDR processes

- Liaison is taking place around contract requirements for care homes to include attendance at training

Sustainability Training being planned is cost neutral. Initiatives have needed time investment, but are reducing duplication and coordinating work better between organisations.

This model and approach has been effective, and could easily be duplicated.

\section{P-239 TOMORROW'S CARERS - HELPING TO UNLOCK THEIR POTENTIAL!}

Tricia Wilcocks, Sue Marshall. ellenor, Gravesend, UK

10.1136/bmjspcare-2016-001245.260

Background The hospice identified previous work placements offered internally provided an inconsistency of experience for learners, with multiple requests placing a burden on care staff, resulting in a review of the model of student support. This closely related to influential factors for future work force planning as follows: increasing demand on health and social care services; growing role of hospices as educators; a need to influence student career choices as early as possible; reluctance to expose young people to direct care.

To extend opportunities, funding was obtained from Health Education England to trial different models of support.

Aims

- Increase number of students experiencing hospice care

- Provide alternative structured training models

- Provide consistent positive experience of care delivery

- Support workforce to stimulate student's experiences.

Approach Comparison of two supported training models:

1. One week accredited course

2. Six month placement. 